\title{
Changing teaching techniques and adapting new technologies to improve student learning in an introductory meteorology and climate course
}

\author{
E. M. Cutrim, D. Rudge, K. Kits, J. Mitchell, and R. Nogueira \\ Western Michigan University, Kalamazoo, MI 49008, USA \\ Received: 15 September 2005 - Revised: 24 February 2006 - Accepted: 5 March 2006 - Published: 6 June 2006
}

\begin{abstract}
Responding to the call for reform in science education, changes were made in an introductory meteorology and climate course offered at a large public university. These changes were a part of a larger project aimed at deepening and extending a program of science content courses that model effective teaching strategies for prospective middle school science teachers. Therefore, revisions were made to address misconceptions about meteorological phenomena, foster deeper understanding of key concepts, encourage engagement with the text, and promote inquiry-based learning. Techniques introduced include: use of a flash cards, student reflection questionnaires, writing assignments, and interactive discussions on weather and forecast data using computer technology such as Integrated Data Viewer (IDV). The revision process is described in a case study format. Preliminary results (self-reflection by the instructor, surveys of student opinion, and measurements of student achievement), suggest student learning has been positively influenced. This study is supported by three grants: NSF grant No. 0202923, the Unidata Equipment Award, and the Lucia Harrison Endowment Fund.
\end{abstract}

\section{Introduction}

College level courses are often taught in large lecture settings $^{1}$, a format that is particularly challenging for both stu-

Correspondence to: E. M. Cutrim

(cutrim@wmich.edu)

${ }^{1} \mathrm{~A}$ "large class" is generally taken to refer to any course that has 100 or more students (c.f. Weiner 1987). Reasonable people may disagree that 100 is the magic number at which a class should be considered large. Clearly much depends upon the context: a section of an introductory freshman writing course might well be considered large if it had over 30 students. For the purposes of this essay, we will refer to a course with an actual enrollment of 85 students as large primarily because the format of the course was developed with dents and instructors. It's widely recognized that large lectures can promote passivity and feelings of anonymity among students. Practical constraints such as time, fixed seating oriented toward a lectern, not to mention the sheer number of students present, may understandably lead instructors to believe they have no choice but to act as if teaching were simply a matter of transmitting information and learning a matter of rote memorization, despite decades of research documenting that learning is a more active process (Bonwell and Eison, 1991; National Research Council, 2000a, b; Donovan and Bransford, 2005). These challenges are further compounded in the context of introductory science content classes taught as survey courses. Students who take such courses often differ greatly from one another in terms of academic program, background preparation, and level of interest. As such, instructors are put in the difficult position of balancing the needs of some students against the needs of others with respect to both the planning and execution of the course. In light of these multiple constraints and tensions, one cannot help but wonder whether there is any practical way to make large lecture survey courses more student-centered and inquiry-based.

The following paper discusses the experiences of a college level instructor of a large lecture survey course (Cutrim) who revised her introductory meteorology and climate class in numerous ways in an attempt to promote more active engagement on the part of her students. These revisions were done with the support of a graduate teaching assistant (Nogueira) and staff (Kits, Mitchell and Rudge) associated with the $\mathrm{E}^{3}$ grant, a large NSF funded grant project aimed at the devel-

reference to a potential enrollment in excess of 100 (i.e. the course is taught primarily by lecture in an auditorium with fixed seating). We have no reason to believe that the instructor's execution of the techniques described here was facilitated by the fact that 15 fewer students signed up for the course than were expected; indeed, we are of the opinion these same techniques would work in introductory meteorology classes of 200 or more.

Published by Copernicus GmbH on behalf of the European Geosciences Union. 
opment of a middle school science teacher preparation program at Western Michigan University (WMU). After briefly describing the course and the reasons that led the instructor to consider how the course might be revised in ways to make it more student-centered and inquiry-based, the essay reviews a series of techniques specifically introduced to promote active learning. It concludes by discussing the rewards, challenges and pitfalls of introducing such techniques into large lecture science content survey courses.

\section{Description of the course}

GEOG 2250 Introduction to Meteorology and Climate is a large lecture survey course taught in a lecture/lab format at Western Michigan University, Kalamazoo, MI. During the Fall and Spring terms, the course had approximately 85 students, but in previous terms the enrollment has been as high as 160. Participants attend a $75 \mathrm{~min}$ lecture twice per week, and $\mathrm{a} 1 \mathrm{~h}$ and $50 \mathrm{~min}$ lab, taught by graduate student teaching assistants (TAs), in sections of 20 students once per week. The course has one formal prerequisite, GEOG 1050 Physical Geography, but presumes participants come with some basic knowledge in algebra and physics, as well as some familiarity with the use of computers.

Like similar courses offered at other universities, GEOG 2250 is intended to promote a basic understanding and application of meteorological concepts and their use in everyday life. The course is intended to sharpen the student's ability to observe and understand both local and global weather phenomena, such as climate change, the ozone hole, and the greenhouse effect. Each lecture begins with a discussion of current weather maps, the output of forecast models, and current weather events over the United States in general, and the Great Lakes region in particular.

The specific objectives for GEOG 2250 are that, by the end of the course, students will:

1. Be able to bridge the gap between the invisible and abstract atmospheric physical processes, and the expression of these processes in the everyday weather events.

2. Understand the relationship between the Earth's orbit as it intercepts the Sun rays, and the role of the Earth's atmosphere on the energy budget of the planet.

3. Understand the role of atmospheric moisture and temperature on the atmospheric static stability and development of clouds.

4. Understand the relationship between the atmospheric pressure and the formation of winds.

5. Analyze surface and high altitude weather maps identifying long waves and short wave patterns and associated atmospheric disturbances and thunderstorms.
6. Understand the anthropogenic and natural sources of air pollutants, and discuss issues in global climate change.

Course content and skills are facilitated by a textbook (Aguado and Burt, 2004), a lab manual (Carbone, 2004), and an associated study guide (Aguado et al., 2001). The text features references to multiple world wide web related resources now available on meteorology and climate topics, and includes a CD ROM containing software tutorials, which utilize 2-D and 3-D animations to promote understanding of atmospheric processes and phenomena presented in chapters. Students are evaluated on the basis of attendance (in class assignments), laboratory assignments, regular quizzes (for each 2 chapters), three midterm exams (each covering 5-6 chapters), and a final exam (remaining chapters). Students are additionally evaluated with respect to a semester group project, intended to stimulate creativity and research, using knowledge acquired in the course. Depending upon their interests, students may use this project to: 1) demonstrate or document meteorological events; 2) identify and solve a real life problem involving weather and climate, or, 3) create atmospheric science curriculum materials for use in K-12 education (for additional information about the course see http://homepages.wmich.edu/ cutrim/teaching1.htm).

The broad objectives of GEOG 2250 (noted above, and alluded to in the preceding description of the semester group project) are indicative of the multiple demands placed upon this course by several distinct academic programs. The course is taken by students majoring in aviation $(\sim 75 \%)$, secondary education $(\sim 10 \%)$, earth sciences, geography, and environmental studies $(\sim 15 \%)$. It is required as part of the aviation sciences curricula, but only an elective for all other majors. There are significant discrepancies among students with regard to their academic preparation. For instance, aviation students are required to take calculus and physics before this class, and understandably want to learn more of the materials related to aviation weather. Students pursuing other majors, in contrast, have less knowledge of basic algebra and for the most part have never taken a physics course. And, as one might expect, some of the course objectives hold greater interest than others depending upon the specific career interests of students. Aviation students are particularly interested in the practical skills associated with making sense of weather information as it relates to the demands of flying airplanes. Secondary education majors, in contrast, are understandably more concerned with developing a basic understanding of meteorological phenomena they will one day need to teach in a middle or high school setting.

\section{Teaching approach prior to course revisions}

Cutrim has taught GEOG 2250 on a regular basis at Western Michigan University since 1993 (22 times total). Prior to her participation on the $\mathrm{E}^{3}$ grant project (discussed below), she taught the course in a traditional large lecture format. She 
used lecture sessions to present new concepts and demonstrate how to solve a few selected problems. She used lab sessions, in contrast, to reinforce concepts and have students practice largely theoretical problems using a lab manual. There was very little interaction between student and instructor, and when there was, it was the instructor who asked questions, with only one or two students responding throughout the term.

Meteorology is the study of physical processes occurring in the atmosphere. The ever changing nature of weather phenomena (both locally and globally) provides multiple opportunities to exemplify and reinforce materials studied in lecture. As a consequence, introductory meteorology courses typically start with discussions of current weather, so that students can increase their awareness of weather phenomena, recognize synoptic patterns to help forecast weather, and make wise decisions when planning outdoor activities. In view of these considerations, Cutrim began her lectures with short presentations of current weather phenomena including satellite image animation from the University of Wisconsin (http://www.ssec.wisc.edu/data/), radar images, surface weather, and upper air analysis from Purdue University (http://weather.unisys.com), and Kalamazoo area weather forecasting from the University of Michigan Weather Underground web site (http://groundhog.sprl.umich.edu). The instructor made presentations of the weather for the first two weeks, after which students, working in groups of four, assumed responsibility. Presenters were initially asked to meet with the instructor in the meteorology laboratory one half hour before lecture for a weather briefing and determining how to divide up the class presentation among group members. This activity was ultimately discontinued in favor of instructor or TA presentations, owing to recurring problems (particularly at the end of the term) with students being unwilling and/or unable to attend the briefing sessions. Students were also concerned about how the activity was graded, particularly when it appeared that one or two had done most of the work. It seems clear that these problems will arise for anyone who uses this technique. With regard to the grade issue, we suggest group members be required to evaluate each other's performance when they do this assignment.

\section{Context of the revision process}

Enlist, Equip And Empower $\left(\mathrm{E}^{3}\right)$ : A Program for the Preparation of Middle School Science Teachers is an integrated approach to improving the quality of middle school science teaching. Developed at WMU and funded by the National Science Foundation, this innovative approach to teacher preparation includes activities aimed at recruiting caring and qualified individuals into the profession, the development of a new program of instruction at WMU specific to the needs of middle school science teachers, and meetings and workshops that empower in-service teachers during the crucial first years of their careers (see www.wmich.edu/ science/e3/index.html).

To teach effectively, middle school science teachers must have a thorough grasp of content, understand how children learn, and be able to use inquiry-based methods (National Commission on Teaching and America's Future, 1996; American Association for the Advancement of Science, 1993). At the start of the grant, WMU, like other institutions throughout the country, had two teacher preparation programs specific to the needs of elementary (grades K-8) and secondary teachers (grades 7-12). The former are required as part of their preparation program to take six science content courses representing the life, earth and physical sciences. The latter major in a particular science. Neither program is sufficient to train future middle school science teachers, who, like elementary teachers, are responsible for teaching science content in all three content areas. Students with elementary certification generally have insufficient science depth. Students with secondary certification only have sufficient science content in one of the three areas they will need to succeed at the middle school level (Young adolescents who attend middle school are also demographically distinct as learners from those in elementary and secondary settings.).

The core of WMU's suggested program of preparation for future middle school science teachers is a six science content course sequence specifically developed for the needs of elementary school teachers. These courses in the earth, physical and life sciences have been developed with reference to state and national benchmarks for scientific literacy and are taught in the form of 24 student lab sections. While not methods courses, the student-centered, inquiry-based pedagogy of these courses is specifically intended to role model how future teachers of elementary classrooms should one day teach. To provide future middle school science teachers with the science content they will need to succeed, participants are encouraged to take a series of additional science content courses that are taught, for a variety of logistic constraints, in the form of traditional large lecture classes. Specific courses were chosen to complement the elementary science content courses mentioned above with reference to state and national benchmarks for science literacy at the middle school level. The $\mathrm{E}^{3}$ project staff approached the instructors of these courses about the possibility of revising pedagogy in ways that would make the courses more student-centered and inquiry-based for the benefit of not only future middle school science teachers (who would always be a distinct minority), but also all other students taking these courses. GEOG 2250 was one of these courses.

The start of the instructor's involvement in the $\mathrm{E}^{3}$ grant coincidentally began just as Unidata launched Integrated Data Viewer, a new tool to acquire real time data and visualize and display geo-referenced weather data in a given projection. This new software not only allowed the instructor (Cutrim) and TA (Nogueira) to create and display weather data in 
E. M. Cutrim et al.: Changing teaching techniques and adapting new technologies to improve student learning

the lecture, but also allowed the development of hands-on, computer-based laboratory exercises.

Cutrim's association with the $\mathrm{E}^{3}$ project began in Fall 2003. Mitchell made classroom observations of the course to familiarize herself with the course and begin the process of documenting classroom dynamics to assist Cutrim during the revision process while baseline data was collected. These observations focused on teaching methods employed, questioning techniques, reception of content and delivery by the students, and the relative success of the teaching methods employed as determined by the impressions of the instructor and the observer. The observations also took note of student misconceptions about science content (or the lack thereof). Mitchell and Cutrim met weekly to discuss these observations and clarify which aspects of the course should continue to be attended to by the classroom observer.

During this time, Cutrim, Mitchell, Rudge, an instructor of a geology course under revision, another $\mathrm{E}^{3}$ staff member assisting this second instructor, and a middle school science teacher in residence on the grant and class observer for this other course, also met on a biweekly basis to discuss science education literature (for a useful bibliography of research on how to promote inquiry in large lecture science content courses, including references specific to earth science education, see Geer and Rudge 2002). These meetings were additionally used to help Cutrim and the instructor of the geology course refine their ideas on what aspects of their respective courses they would like to change, what techniques are available, and how best to implement them. Mitchell continued to make class observations and meet with Cutrim throughout Spring term 2004. In Fall 2004, Kits replaced Mitchell as a classroom observer of Cutrim's class. Cutrim, Rudge and Kits met biweekly to discuss these observations and practical difficulties associated with the implementation of the new techniques.

\section{Techniques introduced}

Four techniques are discussed below. For each technique a brief description of the motivations that led to its introduction is followed by a description of what was involved. The efficacy of these techniques was determined on the basis of Cutrim's reflections, separate observations by Mitchell and Kits, student perceptions (as indicated in an end of term Teaching Techniques survey), and, when possible, student achievement data.

\subsection{Flash card technique}

Previous experiences with GEOG 2250 drew Cutrim's attention to numerous misconceptions on the part of her students regarding basic meteorological phenomena. The following issues were identified, by inviting students to share their an- tecedent understandings of basic meteorological phenomena before presenting new material.

1. The atmosphere is heated from above, not from below.

2. Moist air is heavier than dry air.

3. Water vapor can be seen.

4. Wind speed and wind velocity are the same thing.

5. Seasons are caused by the proximity of the Earth to the sun in different times of the year.

6. Thunder and lightning are two different weather events.

7. Heat lightning is a different form of lightning.

8. All lightning happen from cloud to ground.

9. Westerlies flow from east to west.

10. Moist air cannot be unsaturated air.

11. Fronts do not cause uplift of air.

12. High pressure systems can be at the center of a midlatitude cyclone

13. Coriolis force is strong at the equator

14. Earth angular velocity cannot be easily calculated

Prior to her participation on the $\mathrm{E}^{3}$ project, Cutrim routinely developed questions based upon these misconceptions as a way of motivating her lectures. She is now additionally using these questions for pre- and post- assessment of student learning.

To address misconceptions, as well as provide her with a way of determining how many students hold a given misconception, Cutrim introduced flash cards (c.f. Mazur, 1996; Meltzer and Manivannan, 1996; Manivannan and Meltzer, 1997) into her lectures as follows. She created a series of multiple choice questions which are projected during class with Microsoft PowerPoint ${ }^{T M}$, each with four alternatives (a-d). Each choice is highlighted in a different color (white, green, yellow and pink), which correspond to cards students are provided with at the start of class (specific colors were chosen against the possibility one or more students might be colorblind). The instructor read the questions projected in a large screen and after a few seconds asked the students to raise the card corresponding to his/her answer.

Use of the technique allowed the instructor to assess where her students were at a glance. Her follow-up was crucial. She did not immediately provide the correct answer. If the majority of the students correctly answered the question, the instructor proceeded to the next question. If, however, students were greatly divided, she routinely invited students who selected different answers to explain their choices. This five- to ten-minute exercise was used to instigate instructor-student, 
student-instructor and student-student discussion. Additional motivation for the class discussion was that the students were told that those flashcard questions would be included on exams.

Use of this technique initially met some resistance on the part of students, who appeared to dismiss it as patronizing. Some students who chose the wrong answers appeared to be embarrassed, while others jokingly used all colors to indicate they had no idea what the right answer was. Some turned in envelopes with cards having a single color, apparently to indicate their disdain for the technique. As the semester progressed, however, and students became increasingly aware that some of these questions would appear on the exam, their interest in the flash card discussions increased and students became more accepting of the technique. Increased familiarity with the technique on the part of both the instructor and students led to improved student-instructor communication, as did use of the questions on the exams as an insentive to take these discussions seriously.

Cutrim ultimately found the technique to be helpful as a means of promoting student participation. She believes that part of the success of the technique was that it provided students with an additional incentive to read assigned material ahead of time. Classroom observations suggest that it was effective in getting students more actively involved, although many seemed preoccupied with copying down questions and answers against the possibility the questions would appear on the exam.

Classroom observers (Mitchell and Kits) noticed improvements in classroom dynamics after the flashcard technique was introduced. Baseline observations taken in Fall 2003 document that it was often difficult for Cutrim to get more than one or two students to regularly participate in classroom discussion. The introduction of the flash card technique gave Cutrim a vehicle by which to bring more students into the discussion. Since a given student is in fact participating at a basic level by holding up a colored flashcard, that gave Cutrim an opening to ask that student to participate more fully by explaining and expanding upon his or her answer. In this way, instead of having the same students answer instructor questions class period after class period, students who normally would not volunteer an answer were drawn into the discussion, providing for a better sampling of student understanding and a more lively discussion.

On the Teaching Techniques Survey, students were asked "Do you think the flashcard questions are a positive addition to the class and have helped you to learn? Are there ways that you think the flashcard questions should change so that you could learn better in this class? Explain." Of the 59 students who responded, 37 (63\%) commented that they found the technique was "helpful". One student remarked "it helped me to pay attention more"; while another stated "it facilitates discussion, which helps us as students learn together more effectively." 4 students $(7 \%)$ indicated the flashcards were not helpful, one specifically commenting "most of the questions like the quiz questions are ambiguous and could have more than one clear answer." While 14 students (24\%) indicated that the flashcard technique helped with test preparation, 14 others commented that they took too much time. One student commented "The flashcards are a waste of time because the instructor 'kills' 20-30 min of class time covering a few topics." Among suggested improvements offered by 19 students (32\%), one suggested that "the correct answer should be established first in order to prevent confusion on the correct answer", while another suggested they be posted online first, prior to class. 20 students $(34 \%)$ commented that more flash cards should be used.

\subsection{Reflection questionnaires}

At the beginning of the Fall 2004 semester, Cutrim started soliciting student feedback regarding her pedagogy by means of reflection questionnaires. Students were asked to: 1) list three concepts they had learned in class that changed their beliefs about weather, 2) identify concepts presented in class they felt they still didn't understand, 3) comment on what teaching techniques they most preferred, and 4) describe what they regarded as their most effective study habits. The latter two questions were included only on the first questionnaire and students were encouraged to answer them with respect to all classes they have taken.

Reflection questionnaires were usually administered at the beginning of each class. Answers to the reflection questionnaires gave the instructor a chance to see how much the student had learned, at least in terms of short-term learning, and also a sense of which parts of the material should be reviewed once more in the following class and before exam reviews. Students appreciated the instructor's attempts to tailor her instruction to meet their needs. This technique also served as a convenient way to keep track of class attendance but were counted as part of the class grade. Over the course of the term, while only half of the students regularly participated, of those who did, the instructor noticed that the students were more articulate about where they were getting confused.

\subsection{Writing assignments}

In Fall 2004 , Cutrim also introduced a series of openended/higher thinking level question for each of the 16 book chapters. The objectives were: 1) to make students more accountable for the chapter readings prior to the lecture, 2) to ensure that students were reading, 3) to help students start to think about the readings, and 4) to ask higher order questions on the readings.

She tried four different ways of using these reading questions both in Fall 2004 and Spring 2005: 1) handing them out in advance of using them in lecture, 2) handing them out near the end of class and having students turn in their responses before leaving for the day, 3 ) handing them out near the end of class and having students turn in their responses at the next 
E. M. Cutrim et al.: Changing teaching techniques and adapting new technologies to improve student learning

class, and 4) handing them out at the beginning and inviting students during lecture to answer them by the end of class. Regardless of the alternative, students were encouraged to work with classmates.

Cutrim found this technique was very effective despite the fact it occurred in large classroom with fixed seating. It allowed students to work in small groups of three, come up with a group idea, and subsequently share and discuss their answer with the rest of the class. During these student presentations she gave other groups opportunities to complement their answer as well as disagree and defend their own point of view. She found these group/class discussions were particularly vigorous on the topics of air pollution and climate change.

This technique was particularly effective in engaging students in class discussion. Because the answers for most of the higher order questions on readings would not be found directly from the textbook, students had to think and reflect on their readings. These assignments forced the students read the book and have a more solid understanding of the material. A few students, in the instructor's evaluation at the end of the semester mentioned that this activity "promoted thorough reading and reflection of the chapters leading to longer lasting learning and good grades".

On the Teaching Techniques Survey, students were asked "Do you think that the reading review questions are a positive addition to the class and have helped you to learn? Are there ways that you think the reading review questions should change so that you could learn better in this class? Explain." Of the 59 students who responded, 31 (53\%) indicated they thought these questions were "helpful". One commented "The questions are good at challenging the ideas presented", while another stated "Good because they help us see the important points in the chapter; they also give us more points and help out our grades by doing them." 20 students (34\%) thought they were "not helpful". One commented "The reading review are not graded, they take up a lot of class time and we learn very little from them. They are not taken seriously." 10 students (17\%) thought they helped them prepare for exams.

The survey also specifically asked students to respond to the question "Do you think that the discussion following the reading review questions is a positive addition to the class and has helped you to learn? Are there ways that you think the discussion following the reading review questions should change so that you could learn better in this class? Explain." Of the 59 students who responded, 39 students (66\%) found the discussions following the reading review questions were helpful. One student commented "The discussion is very beneficial; this was probably the most beneficial portion of the class", while another commented "discussing the questions is very helpful because people were actually learning during that time." Among the 12 students (20\%) who disagreed, one commented "Questions are not in a format seen on a test and aren't even corrected for correct answers", while another stated "I don't think this helps as much. If it's in the book, then why should we discuss it?"

\subsection{Interactive discussions on weather and forecast data us- ing IDV}

At the beginning of each lecture students watched a ten minute weather presentation on the analysis of the current weather events and national and local weather forecasts. Weather conditions on the presentations were used as examples to reinforce and/or introduce the abstract physical concepts associated with the course content. Dr. Cutrim also used the Integrated Data Viewer (IDV) to display the realtime weather data. IDV is the freely available software developed by UNIDATA to access and visualize in 3-D real-time weather data-stream, such as satellite image, radar, station model, atmospheric models generated by computers.

The weather presentation started with the last four available infrared GOES satellite images to identify cloudiness areas over the Eastern Pacific ocean, the US and the Caribbean. Next Cutrim and Nogueria overlaid four radar images to identify precipitation regions followed by the display of the computer model output for the sea level pressure to find out the high and low pressure systems acting over the US. This first part was used to provide a general idea of the atmospheric conditions and identify synoptical patterns.

The second part of these presentations featured 6-, 12-, 24-, 36-, and 48-h weather forecasting, using computer model outputs such as Mean Sea Level pressure, total precipitation, 850-hPa isotherms, 850- and 500-hPa geopotential heights, and jet stream isosurfaces. The objective was to relate weather phenomena, such as precipitation and temperature advection, with the surface and upper level patterns. In addition to the weather presentation, students also used IDV in the lab, with exercises to reinforce what they learned in classroom.

Classroom observers (Mitchell and Kits) noted that as more and more technology was added to the weather presentations during lecture, the level of student interest increased. For the most part, the students of GEOG 2250 are of a demographic that has grown up with a proliferation of advanced technology both at home and in the classroom. As such, they appreciated the weather presentations as being both a bridge into their everyday lives and a demonstration of the latest weather technology available. Cutrim would often use the weather presentation to comment on local and international weather phenomena that was of interest to the students, such as hurricanes and thunderstorms. Gallus et al. (2000), discussing a similar use of web-based technology to promote the learning of weather phenomena, also noted an increase in student motivation. In this way, the weather presentations helped students to further understand the real-world applications of the material being introduced in the classroom. 


\section{Conclusions}

While the foregoing remains a work in progress, two conclusions can be drawn from this case study.

First, the introduction of techniques to promote greater student involvement encompasses the sacrifice of both class time and control. In addition to worrying about the logistics of implementation, the instructor must squarely confront the fact that inviting student participation will of necessity involve a series of hard choices regarding how to abridge lectures to make room for alternative uses of class time. This consideration is particularly pressing in the context of survey courses, where multiple demands on the part of distinct academic programs may appear to give the instructor little leeway when it comes to decisions about what content to include and what not to include. We are inclined to think that merely being able to say one has "covered" a topic in lecture is overrated, particularly if, at the end of the day, students have not retained this information (In this, an instructor is akin to a car salesman. By definition, the salesman hasn't had a successful day selling cars unless someone has bought one.). In Cutrim's case, she found she was able to make time for greater student participation by reevaluating her own role in the classroom. Rather than seeing herself as responsible for covering the material in lecture, she has come to recognize herself as a facilitator of learning, and further that ultimately her students must be held responsible for their own learning, if they are to develop as independent learners. In class time contact time with students represents an insurmountable barrier with regard to content only so long as one assumes that unless you cover it in class, students cannot be held responsible for learning it.

Second, given the heterogeneity of students in survey classes (interests, academic preparation, career paths, and learning styles), there is no single technique that will appeal to all students. Invariably some students will see the introduction of new techniques as "busy work" or a waste of time. Part of this reflects the fact that time is being spent on topics they don't find interesting or relevant to their future career plans. But part also reflects the fact that the introduction of these techniques to many students represents a violation of an implicit pact associated with large lecture courses having to do with the roles of instructor and student. As indicated in some of the student quotations above, some students will perceive of these techniques as an abdication of the instructor's responsibility to teach, understood as the dissemination of correct answers for them to memorize. Thus, as difficult as it is for the instructor to develop a level of comfort with the introduction of these techniques and also the sacrifice of control over his/her classroom, the greatest barrier to their successful implementation remains getting students as a group to buy into the objectives that have led the instructor to implement them in the first place. In this regard we think it is very important for instructors to not only brief students on why the interactive technique is being introduced, but also to provide students with multiple opportunities throughout the term to vent their frustrations and revisit fundamental issues associated with teaching and learning. Similar results have been reported by Yarger et al. (2000).

Acknowledgements. This material is based on work supported by the National Science Foundation Grant No. 0202923, the Lucia Harrison Endowment Fund (Grant \# 03-03-37), and a 2003 Unidata Equipment Award. Any opinions, findings and conclusions or recommendations expressed in this material are those of the authors and do not necessarily reflect the views of the National Science Foundation.

Edited by: E. Cutrim, M. Ramamurthy, S. Nativi, and L. Miller Reviewed by: anonymous referees

\section{References}

Aguado, E. and Burt, J.: Understanding weather and climate (3rd ed.), Prentice Hall, Upper Saddle River, NJ, 560pp., 2004.

Aguado, E., Burt, J., Roli, R., and Schmidlin, T.: Study guide (2nd ed.), Prentice Hall, Upper Saddle River, NJ, www.prenticehall. com/aguado, 2001.

American Association for the Advancement of Science: Benchmarks for science literacy, Oxford University Press, New York, 418pp., 1993.

Bonwell, C. C. and Eison, J. A.: Active learning: Creating excitement in the classroom, ASHE- ERIC Higher Education Report No. 1., The George Washington University, School of Education and Human Development, Washington, D.C., 104pp., 1991.

Carbone, G.: Exercises for weather and climate (5th ed.), Prentice Hall, Upper Saddle River, NJ, 203pp., 2004.

Donovan, M. S. and Bransford, J. D. (Eds.): How students learn: History, mathematics and science in the classroom, National Academies Press, Washington, D.C., 615pp., 2005.

Gallus Jr., W. A., Yarger, D. N., and Herzmann, D. E.: An interactive severe weather activity to motivate student learning, Bull. Amer. Meteorol. Soc., 81(9), 2205-2212, 2000.

Geer, U. C. and Rudge, D. W.: A review of research on constructivist-based strategies for large lecture science classes, The Electronic Journal of Science Education, 7(2), http://unr. edu/homepage/crowther/ejse/ejsev7n2.html, 2002.

Manivannan, K. and Meltzer, D. E.: Increasing Student Participation in the Classroom Through the Use of Flash Cards, Proc. ICUPE, AIP, NY Part One, pp. 821, 1997.

Mazur, E.: Peer instruction: Getting students to think in class, in: The changing role of physics departments in modern universities, AIP Conference Proceedings, 399, College Park, MD, pp. 981988, 1996.

Meltzer, D. E. and Manivannan, K.: Promoting Interactivity in Physics Lecture Classes, The Physics Teacher, 34, 72-76, 1996.

National Commission on Teaching and America's Future: What matters most: Teaching for America's future, http://www.nctaf. org/publications/WhatMattersMost.pdf, 1996.

National Research Council: How people learn: Brain, mind, experience and school, National Academies Press, Washington, D.C., 385pp., 2000a. 
National Research Council: Inquiry and the national science education standards: A guide for teaching and learning, National Academies Press, Washington, D.C., 202pp., 2000b.

Weiner, M. G. (Ed.): Teaching Large Classes Well, New Directions for Teaching and Learning, Josey-Bass Inc. San Francisco, CA, 108pp., 1987.
Yarger, D. N., Gallus Jr., W. A., Taber, M., Boysen, J. P., and Castleberry, P.: A forecasting activity for a large introductory meteorology course, Bull. Amer. Meteorol. Soc., 81(1), 31-39, 2000. 